\title{
In vitro intracellular recordings from gustatory neurons in the rat solitary nucleus
}

\author{
Robert M. Bradley ${ }^{1,2}$ and Robert D. Sweazey' \\ ${ }^{1}$ Department of Biologic and Materials Sciences, School of Dentistry, and ${ }^{2}$ Department of Physiology, School of Medicine, The University of \\ Michigan Ann Arbor, MI 48109-1078 (U.S.A.)
}

(Accepted 10 October 1989)

Key words: Nucleus tractus solitarii; Brainstem slice; Taste; Intracellular recording

\begin{abstract}
The passive membrane properties of neurons in the gustatory zone of the nucleus tractus solitarius (NTS) of rats were studied using an in vitro brain slice preparation. Examination of responses evoked by a $0.5 \mathrm{nA}, 100 \mathrm{~ms}$ depolarizing pulse suggests that at least two different types of neurons exist in the gustatory NTS: one responding with a low and the other with a high frequency of action potentials. These two neuron groups based on membrane properties might relate to various gustatory cell types recently categorized by morphological characteristics.
\end{abstract}

Gustatory and visceral afferent fibers of the chorda tympani, glossopharyngeal and vagus nerves terminate on second order neurons in the nucleus tractus solitarius (NTS). Gustatory fibers project to the rostral NTS and visceral afferent fibers terminate more caudally ${ }^{15,24}$. While there have been numerous in vivo and in vitro intracellular recordings from caudal NTS neurons ${ }^{3,6-}$ $8,10,19,20$, comparable data are not available for neurons in the rostral, gustatory NTS. We now report intracellular recordings from neurons in the gustatory zone of the NTS using an in vitro slice preparation of the rat medulla. These intracellular recordings represent the first information concerning the intrinsic membrane properties of neurons in the gustatory zone of the NTS.

Brainstem slices incorporating the rostral gustatory NTS were obtained from rats weighing 90-130 g. Rats were decapitated and the brain was quickly removed and cooled. A block of tissue extending from $8 \mathrm{~mm}$ rostral and $2 \mathrm{~mm}$ caudal to obex was prepared and cemented to a precooled sectioning stage. Coronal slices $400 \mu \mathrm{m}$ thick were then cut on a Vibratome. Slices containing the gustatory portion of the NTS $(1.6-3.0 \mathrm{~mm}$ rostral to obex) were selected for recording. These slices included the principal termination zones of gustatory afferent fibers from the entire oral cavity. After incubation in oxygenated, artificial cerebrospinal fluid ${ }^{18}$ for one hour, individual slices were transferred to the recording chamber ${ }^{14}$. Slices were maintained at $33^{\circ} \mathrm{C}$ and continuously superfused with artificial cerebrospinal fluid at a constant rate of $2 \mathrm{ml} / \mathrm{min}$.
The NTS was easily identified through a dissecting microscope in sections in the slice chamber transluminated from below (Fig. 1A). Intracellular recordings were made using microelectrodes filled with $3 \mathrm{M}$ K-acetate (DC resistance of 70-120 $\mathrm{M} \Omega$ ) connected to bridge amplifier which allowed current injection through the recording electrode. Cells included in this study exhibited stable resting membrane potentials more negative than $-40 \mathrm{mV}$, a spike overshoot, and input resistances greater than $20 \mathrm{M} \Omega$.

We recorded intracellularly from 29 neurons located throughout the gustatory NTS. The majority of cells were situated medial to the descending vestibular fibers which course through the rostral portion of the NTS (Fig. 1). Rostral NTS neurons had resting membrane potentials between -40 and $-70 \mathrm{mV}(\overline{\mathrm{x}}=-52 \pm 1.4 \mathrm{mV}$, S.E.M. $)$. Input resistances, determined from responses to short hyperpolarizing current injections (Figs. 2B, 3B), varied between 21 and $101 \mathrm{M} \Omega(\overline{\mathrm{x}}=55.9 \pm 4.6 \mathrm{M} \Omega)$. The mean membrane time constant was $4.6 \pm 0.4 \mathrm{~ms}$. Action potential amplitude ranged from 50 to $90 \mathrm{mV}(\overline{\mathrm{x}}=67 \pm$ $2 \mathrm{mV}$ ) with a mean duration of $2 \pm 0.1 \mathrm{~ms}$.

Only $17 \%$ of rostral NTS neurons produced spontaneously occurring action potentials $(\overline{\mathrm{x}}=0.6 \pm 0.3$ impulses/s). In spontaneously active cells the discharges occurred singly, were non-rhythmic, and in some cases appeared to arise from spontaneously occurring excitatory postsynaptic potentials. The majority of neurons (23/29) exhibited a prominent afterhyperpolarization $(\overline{\mathrm{x}}$ $=8.8 \pm 0.7 \mathrm{mV}$ ) following spontaneous or evoked action

Correspondence: R.M. Bradley, Department of Biologic and Materials Sciences, School of Dentistry, The University of Michigan, Ann Arbor, MI 48109-1078, U.S.A. 
potentials (Figs. $2 \mathrm{~A}$ and $3 \mathrm{~A}$ ). The mean duration of the afterhyperpolarization was $37.2 \mathrm{~ms} \pm 8.9 \mathrm{~ms}$.

Based on the response to injection of a $0.5 \mathrm{nA}, 100 \mathrm{~ms}$ depolarizing pulse, we were able to separate the neurons into two groups. The majority of neurons tested in this way (17/25) responded with a small burst of $1-4$ action potentials $(\overline{\mathrm{x}}=2.6 \pm 0.3)$ (Fig. 2). These group I neurons generally exhibited increasing interspike intervals between successive action potentials (Fig. 2A), a small increase in the number of action potentials to increasing intensities of short depolarizing pulses (Fig. 2B), and only occasionally had an anodic break spike following injections of hyperpolarizing pulses. Twelve of the group I neurons responded with more than one action potential and these had a mean instantaneous frequency of $70.8 \pm$ 8.9 impulses/s, calculated from the interspike interval between the first and second action potentials.

The responses of the remaining, group II, NTS neurons to a $0.5 \mathrm{nA}, 100 \mathrm{~ms}$ depolarizing pulse varied between 6 and 13 impulses $(\bar{x}=9.1 \pm 0.7)$ (Fig. 3). These neurons generally exhibited only a small increase in the interspike interval between successive spikes. Accommodation in spike amplitude over the course of the burst was frequently observed (Fig. 3A). In addition they had instantaneous frequencies as high as 213 impulses $/ \mathrm{s}(\overline{\mathrm{x}}=$ $128 \pm 13.8)$, and differed from group I neurons in that anodic break spikes were frequently observed following injections of hyperpolarizing current (Fig. 3B). Like group I neurons, group II neurons responded with an increased number of spikes to increments in depolarizing current. Both group I and II neurons exhibited longlasting membrane hyperpolarizations following the elicitation of a burst of action potentials. This postburst afterhyperpolarization varied from $1.6-12 \mathrm{mV}(\overline{\mathrm{x}}=7 \pm$ $0.7 \mathrm{mV}$ ) and had a mean duration of $770 \pm 187 \mathrm{~ms}$.

To our knowledge, these results represent the first intracellular recordings from second order neurons in the gustatory zone of the NTS. These neurons had passive membrane properties similar to those reported for cells in the caudal NTS and in other brain regions $3.6,7.9,16.17 .20$. Examination of responses evoked by a $0.5 \mathrm{nA}, 100 \mathrm{~ms}$ depolarizing pulse suggests that at least two different types of neurons exist in the gustatory NTS: one responding with a low and the other with a high frequency of action potentials.

In slice preparations of the more caudal non-gustatory NTS 3 different neuron types have been described using combined electrophysiological and morphological criteria $^{8}$. The passive membrane properties of neurons in the gustatory NTS described in the present study were most similar to neurons classified as Type III neurons in the non-gustatory NTS.

Another similar characteristic between neurons in the gustatory and non-gustatory NTS, as well as other brain areas, was the afterhyperpolarization which followed individual action potentials and the burst of action potentials produced by a depolarizing current. The hyperpolarizing afterpotentials were especially pronounced after a burst of action potentials and probably result from calcium-activated potassium conductances, an
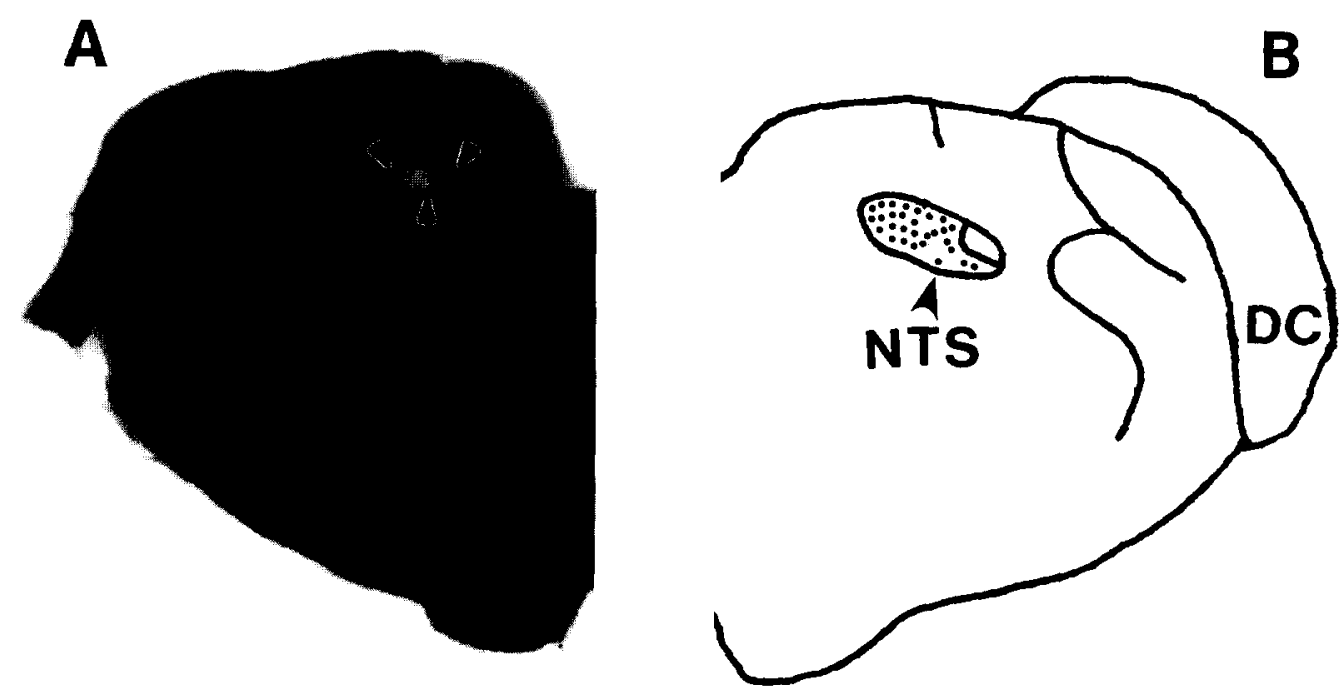

Fig. 1. A: photomicrograph showing one half of a coronal, $400-\mu \mathrm{m}$-thick, rat brainstem slice containing the gustatory NTS. This slice was located about $2.2 \mathrm{~mm}$ rostral to obex. Because of its translucence, the rostral NTS (outlined by the arrowheads) is easily visualized when the slice is illuminated from below. B: schematic drawing of the rat brainstem at approx. the same level as in $A$. Locations of intracellularly characterized neurons are indicated by the filled circles. Although neurons were recorded throughout the facial and glossopharyngeal nerve termination zones in the NTS (from 1.6 to $3.0 \mathrm{~mm}$ rostral to obex), all recording sites have been represented on this one schematic drawing. 

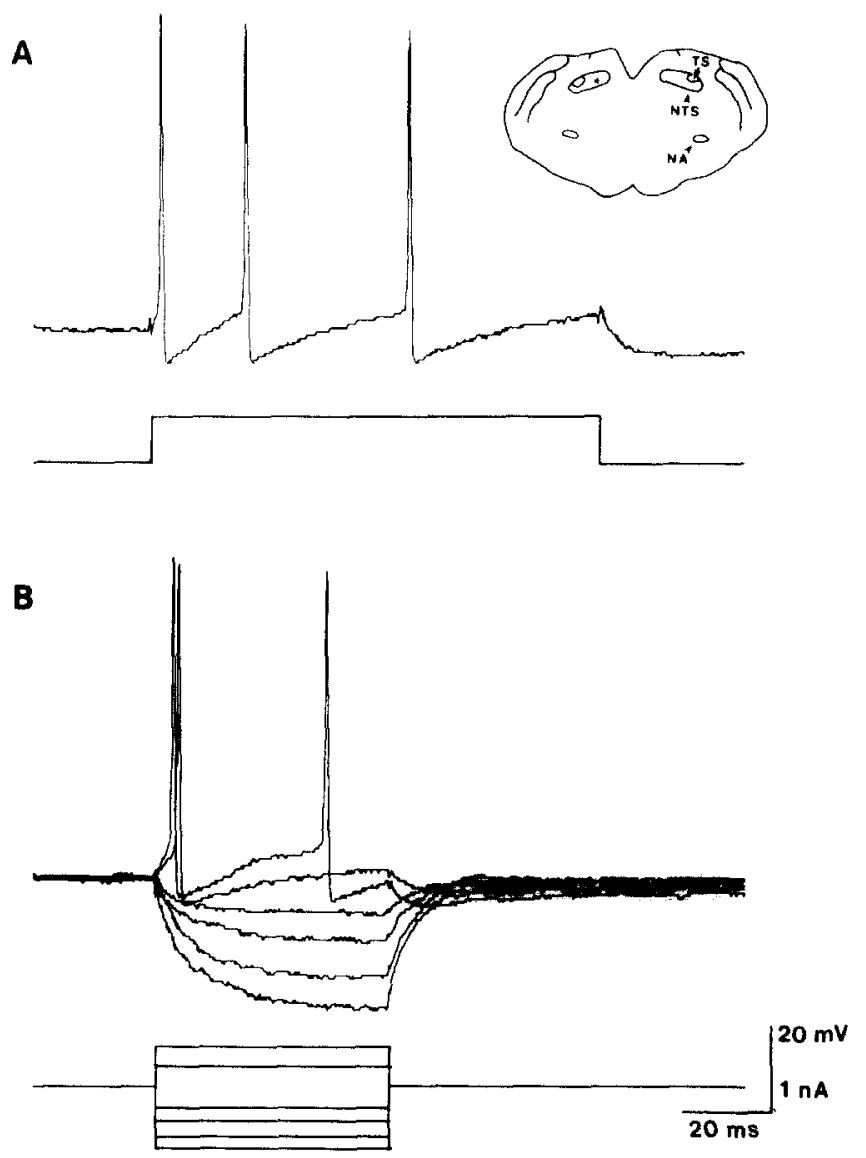

Fig. 2. Responses of a Type I neuron to depolarizing and hyperpolarizing current pulses. A: response to a $0.5 \mathrm{nA}, 100 \mathrm{~ms}$ depolarizing current pulse. Type I neurons responded with 1-4 action potentials to the depolarizing pulse. Note that each action potential is followed by a prominent afterhyperpolarization. $B$ : response of the same neuron to $50 \mathrm{~ms}$ hyperpolarizing and depolarizing pulses. Injections of increasing intensities of depolarizing current resulted in an increasing number of action potentials. The location of this neuron is shown in the schematic drawing at the upper right of the figure, denoted by a star on the left side of the NTS. The calibration bar at the lower right applies to both A and B.

important mechanism for intrinsic control of cell firing ${ }^{1,}$ 13,27

One difference between gustatory NTS neurons and neurons located more caudally in the NTS is reflected in the amount and nature of spontaneous activity. Neurons in the gustatory NTS had little or no spontaneous activity and repetitive patterns of spontaneous activity were never observed. In contrast, neurons in the non-gustatory NTS are often spontaneously active and a number of neurons have repetitive activity ${ }^{2,3,6,8,20}$.

The separation of neuron types based on biophysical measurements complements other studies demonstrating different neuronal populations in the gustatory NTS. Recent morphological studies of the rostral NTS in the hamster have described several neuron types ${ }^{4.5 .26}$. Furthermore, two distinct projection patterns have been described from second order NTS neurons ${ }^{21,22,25}$. One set
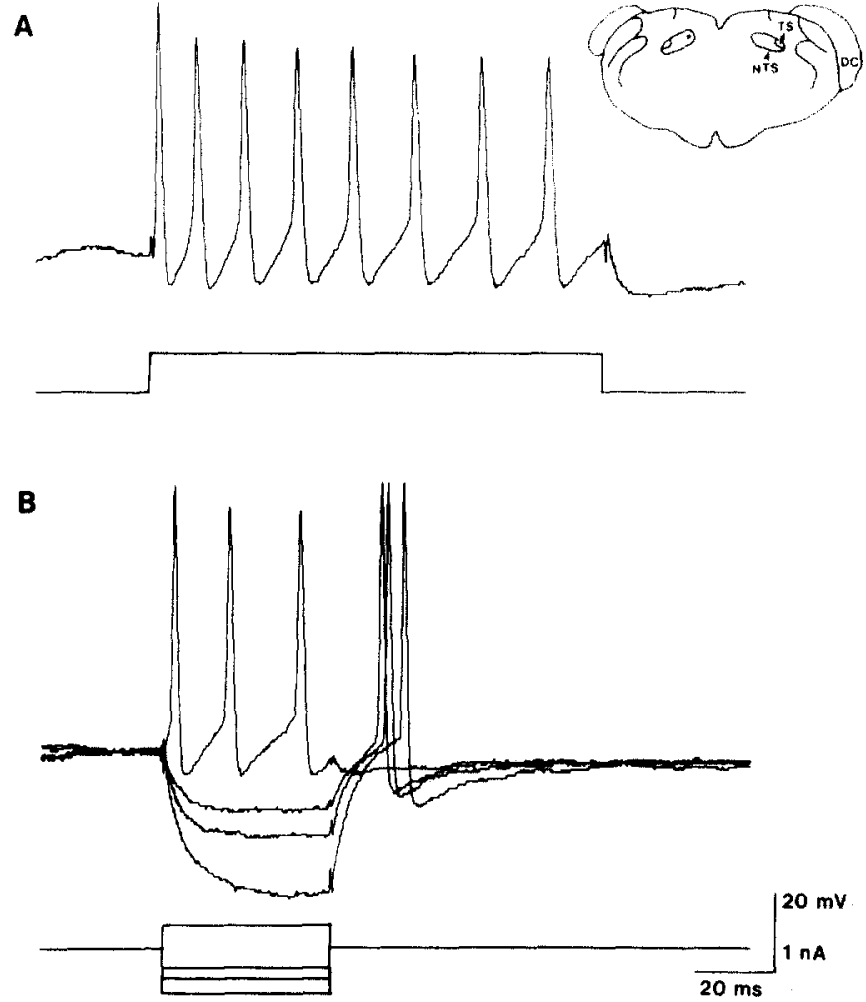

Fig. 3. Responses of a Type II neuron to depolarizing and hyperpolarizing current pulses. A: response to a $0.5 \mathrm{nA}, 100 \mathrm{~ms}$ depolarizing current pulse. Type II neurons responded with a larger number of action potentials to the depolarizing pulse than Type I neurons (Fig. 2A). Note also that some reduction occurs in the action potential amplitude during the burst. $\mathrm{B}$ : response of the same neuron to different levels of current injection. Note that each hyperpolarizing pulse initiated an anodic break spike. Anodic-break spikes occurred more often in Type II than Type I neurons. The location of this neuron in the NTS is shown in the schematic drawing in the upper right corner, denoted by a star on the left side of the NTS

of efferent fibers projects rostrally through the medulla to the pons, and terminates in the pontine taste area (PTA). On the basis of differences in response latencies to antidromic activation of these rostrally projecting NTS neurons, two subsets of projection neurons can be defined ${ }^{23}$. The other set of rostral NTS efferents consists of fibers projecting caudally within the medulla and into the spinal cord, terminating primarily in caudal NTS, the reticular formation subjacent to the NTS, the hypoglossal nucleus, and the reticular formation lateral to the hypoglossal nucleus ${ }^{25}$. Recent studies using retrograde transport of HRP have shown that the two efferent projection systems are anatomically segregated within the NTS. The cell bodies of the rostrally-projecting neurons are located dorsolaterally in the nucleus and the caudallyprojecting neurons are located ventrally ${ }^{25}$.

At present there is no direct information on the gustatory function of these neuron types and associated ascending systems. Experiments with decerebrate rats, in 
which only the brainstem projections from rostral NTS remain intact, have shown that rather complex behavioral responses to taste stimuli can be coordinated with brainstem circuitry ${ }^{11}$. Disruption of the ascending taste pathway, on the other hand, at the level of the PTA or beyond, interferes with taste aversion learning behavior $^{12}$.

In conclusion, despite progress in understanding the morphology and projections of the NTS, little is known regarding the possible functional significance of the

1 Barrett, E.F. and Barrett, J.N., Separation of two voltagesensitive potassium currents, and demonstration of a tetrodotoxin-resistant calcium current in frog motoneurones, J. Physiol. (Lond.), 255 (1976) 737-774.

2 Champagnat, J., Denavit-Saubie, M. and Siggins, G.R., Rhythmic neuronal activities in the nucleus of the tractus solitarius isolated in vitro, Brain Research, 280 (1983) 155-159.

3 Champagnat, J., Siggins, G.R., Koda, L.Y. and Denavit-Saubie, M., Synaptic responses of neurons of the nucleus tractus solitarius in vitro, Brain Research, 325 (1985) 49-56.

4 Davis, B.J. and Jang, T., The gustatory zone of the nucleus of the solitary tract in hamster: light microscopic morphometric studies, Chem. Senses, 11 (1986) 213-228.

5 Davis, B.J. and Jang, T., A Golgi analysis of the gustatory zone of the nucleus of the solitary tract in the adult hamster, J. Comp. Neurol., 278 (1988) 388-396.

6 Dekin, M.S. and Getting, P.A., Firing pattern of neurons in the nucleus tractus solitarius: modulation by membrane hyperpolarization, Brain Research, 324 (1984) 180-184.

7 Dekin, M.S. and Getting, P.A., In vitro characterization of neurons in the ventral part of the nucleus tractus solitarius. II. Ionic basis for repetitive firing patterns, $J$. Neurophysiol, 58 (1987) 215-229

8 Dekin, M.S., Getting, P.A. and Johnson, S.M., In vitro characterization of neurons in the ventral part of the nucleus tractus solitarius. I. Identification of neuronal types and repetitive firing properties, J. Neurophysiol., 58 (1987) 195-214

9 Dudek, F.E., Hatton, G.I. and MacVicar, B.A., Intracellular recordings from the paraventricular nucleus in slices of rat hypothalamus, J. Physiol. (Lond.), 301 (1980) 101-114.

10 Felder, R.B. and Mifflin, S.W., Modulation of carotid sinus afferent input to nucleus tractus solitarius by parabrachial nucleus stimulation, Circ. Res., 63 (1988) 35-49.

11 Grill, H.J. and Norgren, R., The taste reactivity test. II Mimetic responses to gustatory stimuli in chronic thalamic and chronic decerebrate rats, Brain Research, 143 (1978) 281-297.

12 Grill, H.J. and Norgren, R., Neurological tests and behavioral deficits in chronic thalamic and chronic decerebrate rats, Brain Research, 143 (1978) 299-312.

13 Gustafsson, B. and Wigstrom, H., Evidence for two types of afterpolarization in CAl pyramidal cells in the hippocampus, Brain Research, 206 (1981) 462-468.

14 Haas, H.L., Schaerer, B, and Vosmansky, M., A simple different neuronal types. In addition there is little understanding of the synaptic properties of the neurons. The development of an in vitro brain slice preparation to study the gustatory NTS should contribute to acquisition of this missing information and enhance understanding of the role of the NTS in processing gustatory information.

We would like to thank Drs. Michael Behbehani, Glenn Hatton and Hylan Moises for technical help in developing the slice preparation. Supported by NIH Grant DC00288 to R.M.B.

perfusion chamber for the study of nervous tissue slices in vitro, J. Neurosci. Meth., 1 (1979) 323-325.

15 Hamilton, R.B. and Norgren, R., Central projections of gustatory nerves in the rat, $J$. Comp. Neurol., 222 (1984) $560-577$.

16 Kita, T., Kita, H. and Kitai, S.T., Electrical membrane properties of rat substantia nigra compacta neurons in an in vitro slice preparation, Brain Research, 372 (1986) 21-30.

17 Lacaille, J.-C., Mueller, A.L., Kunkel, D.D. and Schwartzkroin, P.A., Local circuit interaction between oriens/alveus interneurons and CAl pyramidal cells in hippocampal slices electrophysiology and morphology, $J$. Neurosci., 7 (1987) 1979 1993.

18 Llinas, R. and Sugimori, M., Electrophysiological properties of in vitro purkinje cell somata in mammalian cerebellar slices, $J$. Physiol. (Lond.), 305 (1980) 171-195.

19 Mifflin, S.W. and Felder, R.B., An intracellular study of time-dependent cardiovascular afferent interactions in nucleus tractus solitarius, J. Neurophysiol., 59 (1988) 1798-1813.

20 Miles, R., Frequency dependence of synaptic transmission in nucleus of the solitary tract in vitro, $J$. Neurophysiol., 55 (1986) 1076-1090.

21 Norgren, R., Projections from the nucleus of the solitary tract in the rat, Neuroscience, 3 (1978) 207-218.

22 Norgren, R. and Leonard, C.M., Ascending central gustatory pathways, J. Comp. Neurol., 150 (1973) 217-238.

23 Ogawa, H., Imoto, T. and Hayama, T., Responsiveness of solitario-parabrachial relay neurons to taste and mechanical stimulation applied to the oral cavity in rats, Exp. Brain Res., 54 (1984) 349-358.

24 Torvik, A., Afferent connections to the sensory trigeminal nuclei, the nucleus of the solitary tract and adjacent structures - an experimental study in the rat. J. Comp. Neurol., 106 (1956) $51-141$.

25 Travers, J.B., Efferent projections from the anterior nucleus of the solitary tract of the hamster, Brain Research. 457 (1988) 1-11.

26 Whitehead, M.C., Neuronal architecture of the nucleus of the solitary tract in the hamster, J. Comp. Neurol., 276 (1988) $547-572$

27 Yarom, Y., Sugimori, M. and Llinas, R., Ionic currents and firing patterns of mammalian vagal motoneurons in vitro, Neuroscience, 16 (1985) 719-737. 